\title{
First record of Bursaphelenchus hildegardae Braasch et al., 2006 (Nematoda) in New Zealand with updated information on morphology, sequencing and a key to species of the eggersi-group
}

\author{
ZENG QI ZHAO ${ }^{1, *}$, MICHAEL SURREY ${ }^{2,5}$, WELLCOME HO ${ }^{2,6}$, MILEN MARINOV $^{3,7}$, CAROLYN BLEACH $^{3,8}$, \\ BRENT ROGAN ${ }^{4,9} \&$ BRETT ALEXANDER ${ }^{2,10}$ \\ ${ }^{1}$ Manaaki Whenua - Landcare Research, 231 Morrin Road, Auckland, New Zealand. \\ ${ }^{2}$ Plant Health \& Environment Laboratory, Ministry for Primary Industries, 231 Morrin Road, Auckland, New Zealand. \\ ${ }^{3}$ Biosecurity Surveillance \& Incursion Investigation Plant Health, Ministry for Primary Industries, 14 Sir William Pickering Drive, \\ Christchurch, New Zealand. \\ ${ }^{4}$ SPS Biota Ltd., PO Box 31589, Lower Hutt, New Zealand. \\ 5 "="mrsurrey@gmail.com; ○ https://orcid.org/0000-0002-8859-467X \\ 6 ”.Wellcome.Ho@mpi.govt.nz; @ https://orcid.org/0000-0002-4464-7581 \\ ${ }^{7}$ 巨"Milen.Marinov@mpi.govt.nz; @ https://orcid.org/0000-0003-3284-2555 \\ 8!"="Carolyn.Bleach@mpi.govt.nz; @ https://orcid.org/0000-0003-1089-328X

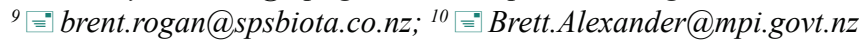 \\ *Corresponding author: "zhaoz@landcareresearch.co.nz; @ https://orcid.org/0000-0002-5347-0669
}

\begin{abstract}
Bursaphelenchus hildegardae Braasch et al., 2006 was collected from pine wood (Pinus radiata) growing in Kaingaroa Timberlands, and a bark beetle, Hylastes ater Paykull, 1800 in New Zealand. This is a new record for B. hildegardae, occuring in New Zealand, and the second report from the southern hemisphere in addition to Australia. In general, the New Zealand isolate of $B$. hildegardae corresponds well with the description of B. hildegardae given by Braasch et al. (2006) from Germany. The New Zealand isolate is characterized by having an adult body length of $807-1190 \mu \mathrm{m}$, medium a ratios (47.5-58.5 for female and 44.6-60.1 for male), b ratios of 9.8-14.5 (female) and 10.2-12.7 (male), c ratios of 18.8-25.2 (female) and 21.6-32.4 (male), c' ratios of 4.0-4.4 (female) and 2.1-2.7 (male), and is characterised by having three incisures in the lateral fields, thorn-shaped spicules with a distinctly dorsally-bent thin hook-like condylus, and a dorso-ventally visible terminal bursa. In addition, molecular phylogeny using near full length small subunit (SSU), D2/D3 expansion segments of the large subunit (LSU) and the internal transcribed spacer region (ITS1 and 2) of the ribosomal rDNA supports the identification. A key to Bursaphelenchus species in the eggersi-group is given.
\end{abstract}

Key words: distribution, molecular, morphology, morphometrics, new record, phylogeny, taxonomy

\section{Introduction}

The genus Bursaphelenchus Fuchs, 1937 is considered an important group for quarantine status globally because of two devastating plant parasitic nematodes, B. xylophilus (Steiner \& Buhrer, 1934) Nickle, 1970 and B. cocophilus (Cobb, 1919) Baujard, 1989. To date, more than 130 species of Bursaphelenchus have been described to science (Kanzaki et al., 2021; Kanzaki \& Giblin Davis, 2018; Ryss et al., 2005; Ryss \& Subbotin, 2017). Two of them, $B$. eggersi Rühm, 1956 and B. fungivorus Franklin \& Hooper, 1962 have been recorded from New Zealand (Dale 1967, 1971; Knight et al. 1997; Yeates, 2010).

Dale (1967) investigated nematodes associated with the pine-bark beetle, Hylastes ater (Paykull, 1800) in New Zealand and found five species: Plectonchus molgos Massey, 1974 (=Anguilluloides zondagi Dale, 1967 synomised by Abolafia et al. (2006)), B. eggersi (Rühm, 1956) Goodey, 1960, Micoletzkya thalenhorsti (Rühm, 1956) Goodey, 1963, Parasitorhabditis ateri (Fuchs, 1937) Rühm, 1956 and Parasitylenchus hylastis (Wfilker, 1923) Filipjev, 1934. Among these species, B. eggersi was isolated from its beetle vector in eight of 14 sites across the North and South Islands of New Zealand, suggesting that it has been established in the country. 
In March 2019, an unexplained mortality of Pinus radiata trees was observed in Kaingaroa Forest in the central North Island of New Zealand during a Forest Health Assessment survey. Close examination in the field of a dead tree failed to determine the cause: the tree trunk was found to be excessively wet, however no obvious fungal disease symptoms or insect damage were found. Subsequently, a group of three trees and a single dead tree were felled and wood disks showing sapstain and heavy waterlogged sections, along with beetles, were sampled for nematode diagnostics. Nematodes were isolated from the wood disks and beetle vector, H. ater.

The New Zealand Ministry for Primary Industries (MPI) initiated a biosecurity investigation and a delimiting survey within Kaingaroa Forest to establish the area of spread and host range of the nematodes. At the early phase of investigation, Kaingaroa Timberlands Ltd. ceased all operational activities and closed off a significant area of forest around the detection site to ensure that any potential biosecurity risk was contained. This action also supported the field survey operations.. The present study provides results, adds to the morphological and molecular diagnostics of the nematode species established and comments on the status in the country.

\section{Material and Methods}

The initial sample was collected during a Forest Heath Assessment Survey conducted by SPS Biota Ltd. The sampling was organised in order to study the possible reasons for the observed tree mortality of Pinus radiata in Kaingaroa Forest in March 2019. Subsequently, material for the present study was collected mainly in April 2019. In total, more than 158 wood discs from 158 trees and 50 beetles were collected within a $3.8 \mathrm{~km}$ radius from the initial detection site. In addition to fresh material, 20 dried specimen of $H$. ater collected prior 2002 were obtained from SCION New Zealand collections and tested for the presence of nematodes.

\section{NEMATODE COLLECTION}

Nematode extraction and specimen processing. Nematodes were extracted from pine wood samples using a variant of the Whitehead \& Hemming (1965) method. Dried specimens of $H$. ater were dissected for extraction of nematodes. For morphological study, nematodes were heat killed and mounted on slides (Davies \& GiblinDavis, 2004). Some were mounted in water as temporary specimens and others were mounted in glycerol as permanent specimens. Morphological characteristics of these nematodes were studied using interference contrast microscopy (Nikon, Eclipse 90i). Measurements of material mounted in glycerol were made using a NIS-Elements Basic Research microscope (Nikon, Version 2.32). Maximum body diameter was measured at mid-length for males and female, respectively. Body length was measured along the mid-line. De Man's ratios were determined, and a camera attached to the microscope (Nikon Camera Head DS-Fi1) was used to take a series of digital images of the specimens (Zhao et al., 2015).

\section{MOLECULAR METHODS}

DNA extraction. Nematodes isolated from Kaingaroa Forest were studied for molecular. A single juvenile, dauer larvae, a male, and a female were each used separately for the extraction of DNA. The method of Zheng et al. (2002) was followed for DNA extraction. Total genomic DNA from each nematode was extracted using worm lysis buffer containing proteinase $\mathrm{K}$ (Williams et al., 1992).

Polymerase chain reaction (PCR), PCR product purification and DNA sequencing. The internal transcribed spacer (ITS), rDNA D2/D3 expansion segments of the large subunit (LSU) and two fragments of rDNA small subunit (SSU) were amplified and sequenced using the primer pairs ITS5 + ITS26 (White et al., 1990), D2A + D3B (Nunn, 1992), 1096F + 1912R (Holterman et al. 2006), and 1813F + 2646R (Holterman et al. 2006), respectively. The $20 \mu \mathrm{l}$ PCR reactions contained $10 \mu 1$ 2x Go Tag ${ }^{\circledR}$ Green Master Mix (Promega Corporation, Madison, WI, USA), $1 \mu 1(5 \mu \mathrm{M})$ each forward and reverse primer and $2 \mu 1$ of DNA template. The thermal cycling programme was: denaturation at $95^{\circ} \mathrm{C}$ for $3 \mathrm{~min}$, followed by 40 cycles of denaturation at $95^{\circ} \mathrm{C}$ for $15 \mathrm{sec}$, annealing at $55^{\circ} \mathrm{C}$ for $15 \mathrm{sec}$ and extension at $72^{\circ} \mathrm{C}$ for $30 \mathrm{sec}$. A final extension was performed at $72^{\circ} \mathrm{C}$ for $7 \mathrm{~min}$. The amplicons 
were electrophoresed on $1.2 \%$ agarose gel (in $1 \mathrm{x}$ TAE) stained with $\mathrm{SYBR}^{\circledR}$ safe, and visualised using a Gel Doc Software system (BioRad, Hercules, CA, USA). Successfully amplified products were sequenced bi-directionally using the amplification primers by EcoGene ${ }^{\circledR}$ (Auckland, New Zealand). The obtained DNA sequences were edited and aligned using Geneious Pro 7.1.5 (Biomatters, Auckland, New Zealand), and a BLAST search was conducted against the GenBank database (Altschul et al., 1990). The sequences were deposited in GenBank with the accession numbers MZ553929 (SSU), MZ542475 (LSU), MZ542474 (ITS).

Sequence alignment and phylogenetic inference. Some published sequences of Bursaphelenchus including all from the eggersi-group for SSU (13 sequences), D2D3 (21) and ITS (22) from GenBank were included in the phylogenetic analysis. Nematode species and GenBank accession numbers are listed for each taxon in the phylogenetic trees (Figs 4-6). DNA sequences were aligned in ClustalX2 (Larkin et al., 2007) using default parameter values. ModelTest 3.04 (Posada \& Crandall, 1998) and PAUP*4.0b10 (Swofford, 1998) were used to select the best fitting model using the Akaike Information Criterion (AIC). A Bayesian phylogenetic tree was constructed using MrBayes 3.1.2 (Ronquist \& Huelsenbeck, 2003) with four MCMC chains run for 1,100,000 generations. The best fitting model for SSU was GTR $+\mathrm{I}+\mathrm{G}$ and GTR $+\mathrm{G}$ for D2D3 and ITS. Prior distributions were as follows: revmatpr $=$ dirichlet $(1,1,1,1,1,1)$, shapepr $=$ exponential (5), brlenspr $=$ unconstrained: exponential (10). We started the analysis from a random topology using a temperature of 0.2 , and a burn-in of $10 \%$ of trees. More details of these methods were described in Zhao \& Buckley (2009).

\section{Results}

Bursaphelenchus hildegardae was found in wood samples (Pinus radiata) and $H$. ater beetles collected in the Kaingaroa Forest from March to April 2019. Extraction of 158 wood samples showed 6 to be containing $B$. hildegardae giving an average presence of about $3.8 \%$, and examination of 50 beetles showed 3 to be carrying $B$. hildegardae giving an average incidence of about $6 \%$. Subsequently, B. hildegardae was also found in beetle samples (H. ater) collected from Victoria Forest near Reefton on 28 April 2019; pine forest near Tikokino on 20 May 2020; pine wood samples (Pinus radiata) from Golden Downs, Nelson forests on 23 October 2020, and Douglas fir (Pseudotsuga menziesii) from Waipori, Dunedin on 11 November 2020, respectively (Table 1).

TABLE 1. Information of Bursaphelenchus hildegardae isolated in New Zealand.

\begin{tabular}{|c|c|c|c|c|}
\hline $\begin{array}{l}\text { Sample } \\
\text { Acc. no }\end{array}$ & B. hildgardae & Specimen & Host \& collecting date & Locality \& Crosby region \\
\hline T19_02339 & $\begin{array}{l}\text { Present, ID confirmed by } \\
\text { morphology, SSU, LSU \& } \\
\text { ITS sequences. }\end{array}$ & $\begin{array}{l}\text { Wood discs, } \\
\text { living beetles }\end{array}$ & $\begin{array}{l}\text { Pinus radiata, Hylastes ater } \\
20 \text { March - } 23 \text { April } 2019\end{array}$ & $\begin{array}{l}\text { Taupo. TO. } \\
\text { Matea Forest; CPT 0879; } \\
\text { Kaingaroa Timberlands. } \\
\text { BP. }\end{array}$ \\
\hline T19_04309 & $\begin{array}{l}\text { Present, ID confirmed by } \\
\text { LSU \& ITS sequences. }\end{array}$ & Living beetles & $\begin{array}{l}\text { Hylastes ater } \\
28 \text { April } 2019\end{array}$ & $\begin{array}{l}\text { Victoria Forest near } \\
\text { Reefton. BR. }\end{array}$ \\
\hline T20_01072 & $\begin{array}{l}\text { Present, ID confirmed by } \\
\text { morphology. }\end{array}$ & Living beetles & $\begin{array}{l}\text { Hylastes ater } \\
20 \text { May } 2020\end{array}$ & $\begin{array}{l}\text { Gwavas Forest, Tikokino, } \\
\text { RI. }\end{array}$ \\
\hline T20_03267 & $\begin{array}{l}\text { Present, ID confirmed } \\
\text { morphology. }\end{array}$ & Wood discs & $\begin{array}{l}P \text {. radiata } \\
23 \text { October } 2020\end{array}$ & $\begin{array}{l}\text { Golden Downs Forest, } \\
\text { Nelson. NN. }\end{array}$ \\
\hline T20_02634 & $\begin{array}{l}\text { Present, ID confirmed } \\
\text { morphology. }\end{array}$ & Wood discs & $\begin{array}{l}\text { Pseudotsuga menziesii } \\
11 \text { November } 2020\end{array}$ & $\begin{array}{l}\text { Waipori Forest, Dunedin, } \\
\text { DN. }\end{array}$ \\
\hline
\end{tabular}

Bursaphelenchus eggersi, which has been reported as established in New Zealand by Dale 1967, has not been found on pine samples or insect vectors received from the delimiting survey carried out during the biosecurity investigation. In addition, $B$. eggersi has not been found from preserved specimens collected by SCION prior to 2002. The morphology of $B$. hildegardae, which is similar to B. eggersi, is provided below. 


\section{Bursaphelenchus hildegardae}

(Figs. 1-6)

\section{Measurements}

See Table 2.

TABLE 2. Morphometrics of Bursaphelenchus hildegardae isolated from Kaingaroa Forest and Waipori Forest New Zealand. Measurements are in $\mu \mathrm{m}$ and in the form: mean \pm SD (range).

\begin{tabular}{|c|c|c|c|c|c|}
\hline \multirow[b]{2}{*}{ Character } & \multicolumn{3}{|c|}{ Kaingaroa Forest (Pinus radiata) } & \multicolumn{2}{|c|}{ Waipori Forest (Pseudotsuga menziesii) } \\
\hline & Female & Male & $\begin{array}{c}\text { Dauer } \\
\text { juvenile }\end{array}$ & $\begin{array}{l}\text { T20-06234 } \\
\text { female }\end{array}$ & $\begin{array}{l}\text { T20-06234 } \\
\text { male }\end{array}$ \\
\hline $\mathrm{n}$ & 7 & 7 & 5 & 5 & 3 \\
\hline $\mathrm{L}$ & $\begin{array}{c}980 \pm 170 \\
(807-1250)\end{array}$ & $\begin{array}{c}942 \pm 131 \\
(839-1163)\end{array}$ & $\begin{array}{c}594 \pm 25 \\
(582-635)\end{array}$ & $\begin{array}{c}1149 \pm 102 \\
(1060-1149)\end{array}$ & $\begin{array}{c}994 \pm 64 \\
(929-1059)\end{array}$ \\
\hline $\mathrm{a}$ & $\begin{array}{c}51.9 \pm 3.6 \\
(47.5-58.5)\end{array}$ & $\begin{array}{c}51.5 \pm 5.2 \\
(44.6-60.1)\end{array}$ & $\begin{array}{c}31.1 .8 \pm 0.8 \\
(30.3-32.2)\end{array}$ & $\begin{array}{c}49.1 \pm 6.3 \\
(41.0-49.1)\end{array}$ & $\begin{array}{c}51.0 \pm 3.3 \\
(47.3-53.1)\end{array}$ \\
\hline $\mathrm{b}$ & $\begin{array}{c}11.6 \pm 1.4 \\
(9.8-14.5)\end{array}$ & $\begin{array}{c}11.3 \pm 0.9 \\
(10.2-12.7)\end{array}$ & $\begin{array}{c}10.3 \pm 1.9 \\
(7.7-12.5)\end{array}$ & $\begin{array}{c}14.0 \pm 1.4 \\
(12.7-14.0)\end{array}$ & $\begin{array}{c}12.2 \pm 0.3 \\
(11.8-12.4)\end{array}$ \\
\hline $\mathrm{c}$ & $\begin{array}{c}21.8 \pm 2.4 \\
(18.8-25.2)\end{array}$ & $\begin{array}{c}28.4 \pm 3.7 \\
(21.6-32.4)\end{array}$ & $\begin{array}{c}16.6 \pm 1.9 \\
(15.4-16.3)\end{array}$ & $\begin{array}{c}27.7 \pm 3.6 \\
(23.6-27.7)\end{array}$ & $\begin{array}{c}34.9 \pm 3.7 \\
(31.9-39.0)\end{array}$ \\
\hline$c^{\prime}$ & $\begin{array}{c}4.2 \pm 0.1 \\
(4.0-4.4)\end{array}$ & $\begin{array}{c}2.3 \pm 0.2 \\
(2.1-2.7)\end{array}$ & $\begin{array}{c}3.7 \pm 0.3 \\
(3.3-3.9)\end{array}$ & $\begin{array}{c}3.7 \pm 0.4 \\
(3.3-3.7)\end{array}$ & $\begin{array}{c}2.0 \pm 0.2 \\
(1.8-2.1)\end{array}$ \\
\hline $\mathrm{V} / \mathrm{T}$ & $\begin{array}{c}73.6 \% \\
(73.2-74.0) \%\end{array}$ & $\begin{array}{c}49 \% \\
(44.9-54.8) \%\end{array}$ & - & $\begin{array}{c}73.3 \% \\
(72.6-73.3) \%\end{array}$ & $\begin{array}{c}71 \% \\
(69.4-73.1) \%\end{array}$ \\
\hline Greatest body diam. & $\begin{array}{c}18.8 \pm 2.1 \\
(16.9-22.1)\end{array}$ & $\begin{array}{c}18.3 \pm 1.4 \\
(16.8-19.6)\end{array}$ & $\begin{array}{c}19.1 \pm 1.2 \\
(18.1-20.6)\end{array}$ & $\begin{array}{c}23.5 \pm 2.2 \\
(21.7-23.5)\end{array}$ & $\begin{array}{c}19.5 \pm 0.7 \\
(18.7-20.1)\end{array}$ \\
\hline Body diam. at anus & $\begin{array}{c}10.7 \pm 1.1 \\
(9.2-12.1)\end{array}$ & $\begin{array}{c}14.4 \pm 0.9 \\
(13.5-15.5)\end{array}$ & - & $\begin{array}{c}11.3 \pm 0.8 \\
(10.5-11.3)\end{array}$ & $\begin{array}{c}14.7 \pm 0.8 \\
(14.1-15.5)\end{array}$ \\
\hline Head region height & $\begin{array}{l}2.5 \pm 3.7 \\
(2.6-3.7)\end{array}$ & $\begin{array}{c}2.7 \pm 0.4 \\
(2.1-3.2)\end{array}$ & - & $\begin{array}{l}2.7 \pm 0.5 \\
(2.4-2.9)\end{array}$ & $\begin{array}{l}2.8 \pm 0.2 \\
(2.5-2.9)\end{array}$ \\
\hline Head region diam. & $\begin{array}{c}7.6 \pm 0.4 \\
(7.2-8.3)\end{array}$ & $\begin{array}{c}7.6 \pm 0.4 \\
(7.2-8.0)\end{array}$ & - & $\begin{array}{c}7.2 \pm 1.1 \\
(5.4-7.2)\end{array}$ & $\begin{array}{c}6.5 \pm 0.3 \\
(6.3-6.9)\end{array}$ \\
\hline Stylet & $\begin{array}{c}13.5 \pm 0.8 \\
(12.4-14.4)\end{array}$ & $\begin{array}{c}13.3 \pm 0.9 \\
(12.1-14.5)\end{array}$ & - & $\begin{array}{c}15.1 \pm 0.8 \\
(14.4-15.1)\end{array}$ & $\begin{array}{c}14.9 \pm 0.6 \\
(14.6-15.6)\end{array}$ \\
\hline Stylet cone & $\begin{array}{c}6.1 \pm 0.6 \\
(5.4-6.4)\end{array}$ & $\begin{array}{c}5.7 \pm 0.8 \\
(4.2-6.2)\end{array}$ & - & $\begin{array}{c}6.8 \pm 0.6 \\
(6.1-6.8)\end{array}$ & $\begin{array}{c}6.4 \pm 0.5 \\
(6.1-6.8)\end{array}$ \\
\hline Ant. end to metacorpus & $\begin{array}{c}84.6 \pm 10.2 \\
(77.4-107.1)\end{array}$ & $\begin{array}{c}83.0 \pm 4.8 \\
(77.8-91.7)\end{array}$ & $\begin{array}{c}59.5 \pm 10.4 \\
(51.4-74.4)\end{array}$ & $\begin{array}{c}82.1 \pm 3.1 \\
(79.4-82.1)\end{array}$ & $\begin{array}{c}81.6 \pm 3.6 \\
(78.6-85.6)\end{array}$ \\
\hline Metacorpus length & $\begin{array}{c}19.6 \pm 1.1 \\
(18.8-21.6)\end{array}$ & $\begin{array}{c}19.1 \pm 1.4 \\
(16.8-20.9)\end{array}$ & $\begin{array}{c}16.9 \pm 0.4 \\
(16.4-17.4)\end{array}$ & $\begin{array}{c}19.2 \pm 1.0 \\
(17.4-19.2)\end{array}$ & $\begin{array}{c}17.3 \pm 0.5 \\
(16.8-17.7)\end{array}$ \\
\hline Metacorpus diam. & $\begin{array}{c}12.6 \pm 0.7 \\
(12.1-13.6)\end{array}$ & $\begin{array}{c}12.1 \pm 1.2 \\
(10.9-14.5)\end{array}$ & $\begin{array}{c}10.9 \pm 1.2 \\
(8.7-11.7)\end{array}$ & $\begin{array}{c}13.2 \pm 0.9 \\
(11.6-13.2)\end{array}$ & $\begin{array}{c}12.1 \pm 0.3 \\
(11.8-12.4)\end{array}$ \\
\hline Metacorpus valve length & $\begin{array}{c}5.6 \pm 0.5 \\
(5.1-6.0)\end{array}$ & $\begin{array}{c}5.1 \pm 0.9 \\
(4.3-5.9)\end{array}$ & $\begin{array}{c}3.8 \\
(2.9 ; 4.7)\end{array}$ & $\begin{array}{c}5.9 \pm 0.5 \\
(5.2-5.9)\end{array}$ & $\begin{array}{c}5.6 \pm 0.2 \\
(5.4-5.7)\end{array}$ \\
\hline Metacorpus valve width & $\begin{array}{c}4.0 \pm 0.2 \\
(3.9-4.2)\end{array}$ & $\begin{array}{c}3.8 \pm 0.5 \\
(3.3-4.7)\end{array}$ & $\begin{array}{c}2.8 \\
(2.3 ; 3.4)\end{array}$ & $\begin{array}{c}4.1 \pm 0.3 \\
(3.7-4.1)\end{array}$ & $\begin{array}{c}3.5 \pm 0.6 \\
(2.9-3.9)\end{array}$ \\
\hline $\begin{array}{l}\text { Anteroir end to end of } \\
\text { gland lobe }\end{array}$ & $\begin{array}{c}175.6 \pm 19.2 \\
(174.0-203.0)\end{array}$ & $\begin{array}{c}157.5 \pm 10.0 \\
(142.1-161.4)\end{array}$ & - & $\begin{array}{c}172.1 \pm 14.6 \\
(153.9-172.1)\end{array}$ & $\begin{array}{c}168.4 \pm 13.3 \\
(153.3-178.3)\end{array}$ \\
\hline $\begin{array}{l}\text { Excretory pore from } \\
\text { anteroir end }\end{array}$ & $\begin{array}{c}104.1 \pm 9.9 \\
(93.3-119.1)\end{array}$ & $\begin{array}{c}106.6 \pm 6.8 \\
(100.1-114.5)\end{array}$ & - & $\begin{array}{c}114.9 \pm 5.0 \\
(109.2-114.9)\end{array}$ & $\begin{array}{c}102.4 \pm 5.3 \\
(96.2-105.6)\end{array}$ \\
\hline Tail length & $\begin{array}{c}44.7 \pm 3.6 \\
(40.2-50.2)\end{array}$ & $\begin{array}{c}33.3 \pm 3.5 \\
(29.1-36.7)\end{array}$ & $\begin{array}{c}36.0 \pm 41.2 \\
(34.2-40.4)\end{array}$ & $\begin{array}{c}41.7 \pm 2.5 \\
(39.2-41.7)\end{array}$ & $\begin{array}{c}28.7 \pm 3.0 \\
(25.5-31.5)\end{array}$ \\
\hline Postuterine sac & $\begin{array}{l}129 \pm 29.6 \\
(97-183)\end{array}$ & - & & $\begin{array}{l}168 \pm 30 . .6 \\
(132-128)\end{array}$ & - \\
\hline Spicule & - & $\begin{array}{c}21.5 \pm 3.1 \\
(17.8-24.1)\end{array}$ & & - & $\begin{array}{c}21.6 \pm 2.0 \\
(20.3-23.9)\end{array}$ \\
\hline Testis & - & $\begin{array}{c}447.2 \pm 71.4 \\
(377.6-507.6)\end{array}$ & - & - & $\begin{array}{c}706.4 \pm 42.2 \\
(657.9-734.5)\end{array}$ \\
\hline
\end{tabular}




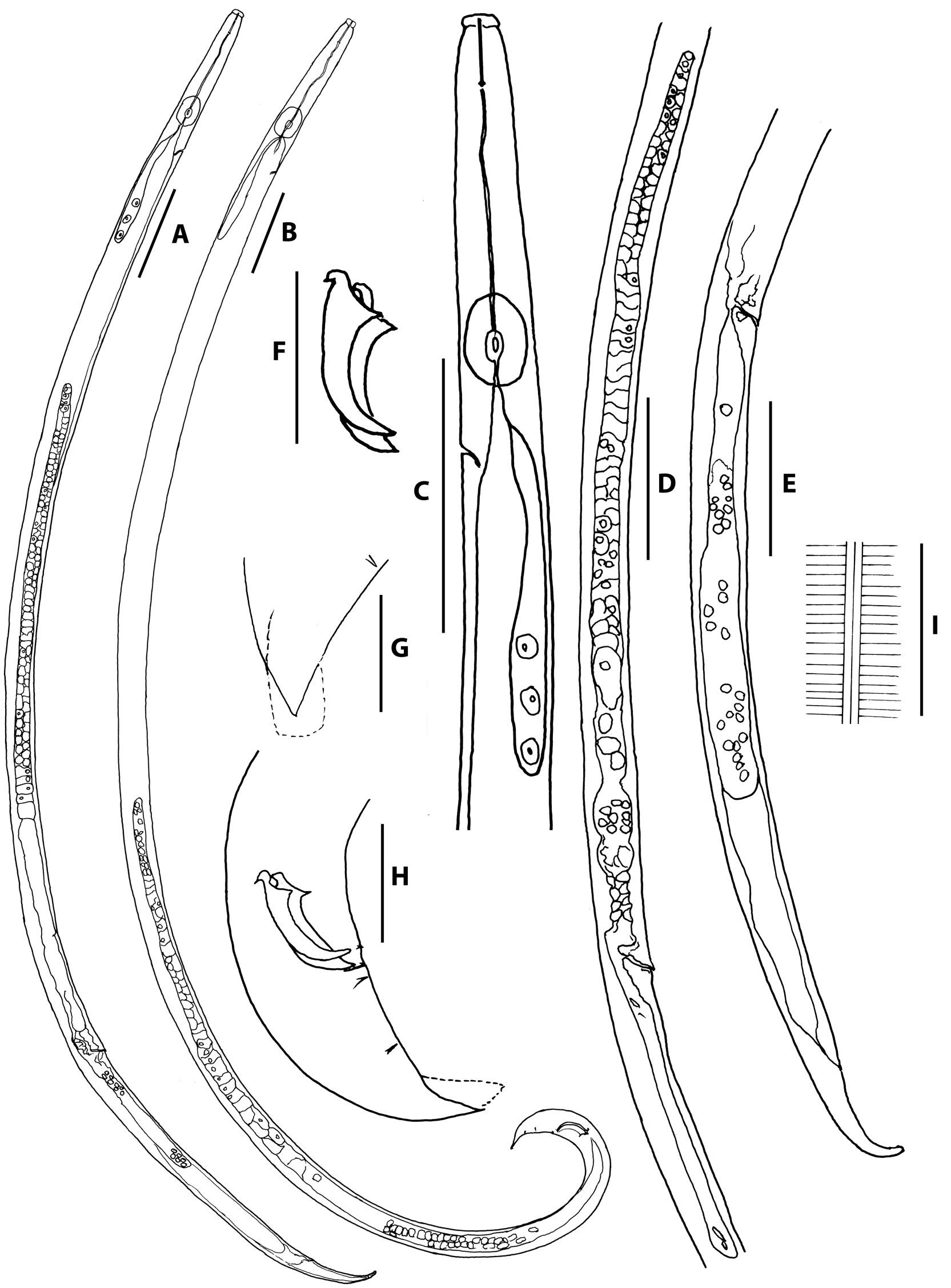

FIG. 1. Bursaphelenchus hildegardae. A: Female; B: Male; C: Anterior part of female; D: Reproductive system of female; E: Posterior part of female; F: Spicules; G: Bursa; H: Posterior end of male; I: Lateral lines. (Scale bars: A-C = 50 $\mu \mathrm{m}$; D-I = 20 $\mu \mathrm{m})$ 


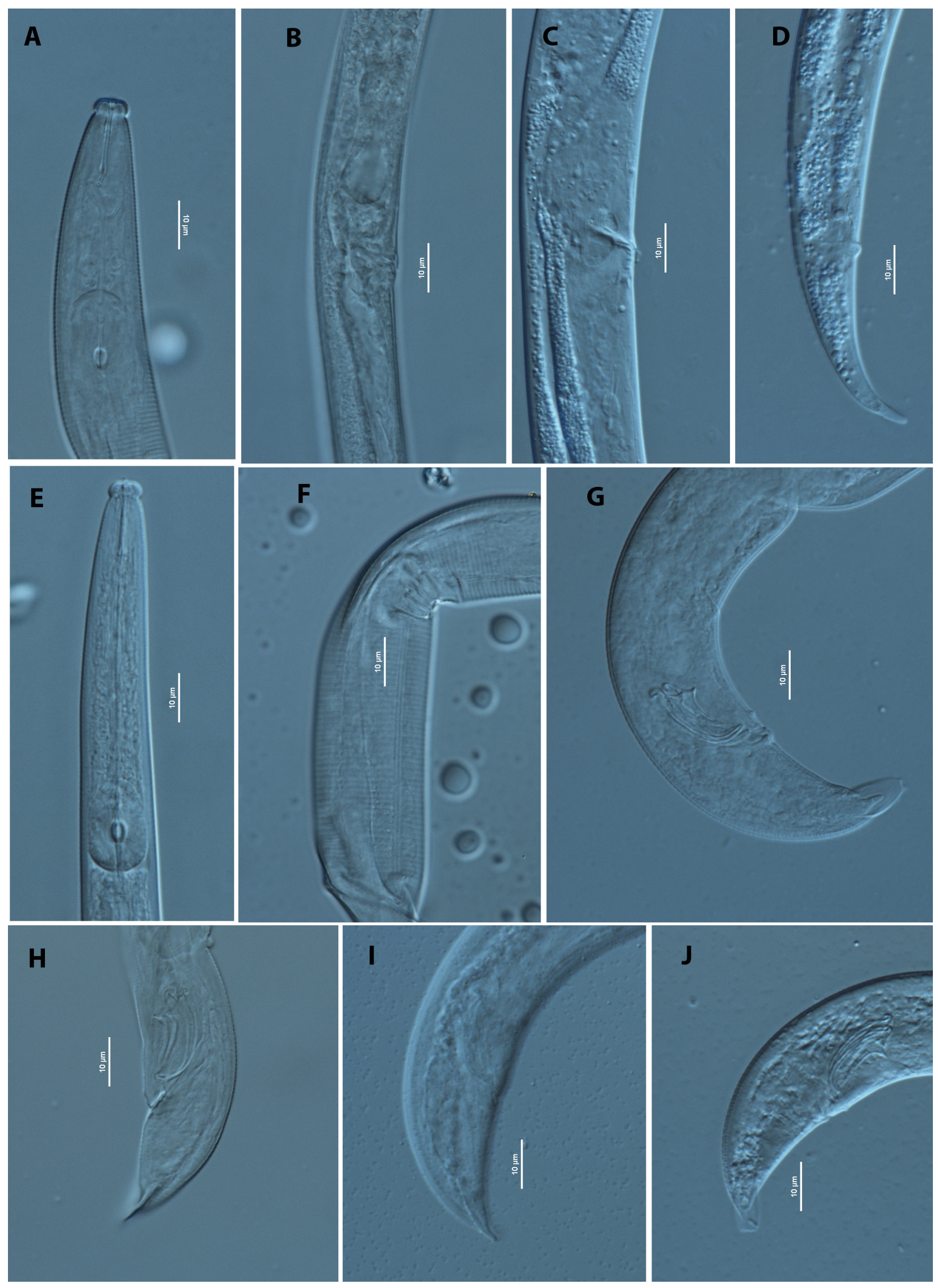

FIG. 2. Light microscope photographs of Bursaphelenchus hildegardae. A: Anterior part of female; B-C:Vulva with flap; D: Female tail; E: Anterior part of male; F: Male lateral lines; G-J: Male spicules, busa \& Tail. (Scale bars: A-J = $10 \mu \mathrm{m})$ 


\section{DESCRIPTION}

\section{Adults}

Body length ranging from 839-1163 and 807-1250 $\mu \mathrm{m}$ for male and female, respectively. Body cylindrical, moderate to slender, i.e., $\mathrm{a}=44.6-60.1$ and 41.0-58.5 for male and female, respectively. Cuticle thin, annulated, lateral field bearing three lines, i.e., two ridges. Head distinctly offset from body, separated by a clear constriction (Figs. 1A, B \& C; 2A \& E). Stylet with narrow lumen comprising a short cone ca 39\% - 45\% of total stylet length and a shaft with slightly clear basal swelling. Procorpus cylindrical, ending in well-developed median bulb, i.e., $19.6 \mu \mathrm{m}$ in length $\mathrm{x} 12.6 \mu \mathrm{m}$ in width for female and $19.1 \mu \mathrm{m}$ in length $\mathrm{x} 12.1 \mu \mathrm{m}$ in width for male. Metacorpal valve clearly observed, i.e., 5.1-6.0 $\mu \mathrm{m}$ in length $\mathrm{x} 3.9-4.3 \mu \mathrm{m}$ in width for female and $4.2-5.9 \mu \mathrm{m}$ in length $\mathrm{x}$ 3.3-4.7 $\mu \mathrm{m}$ in width for male, located at middle of, or slightly posterior to, centre of median bulb. Dorsal esophageal gland orifice opening into lumen of metacorpus mid-way between anterior end of metacorpal valve and anterior end of metacorpus. Pharyngo-intestinal junction ca 3.5-6.0 $\mu \mathrm{m}$ posterior to median bulb. Dorsal pharyngeal glands overlapping intestine dorsally, extending ca 154-203 $\mu \mathrm{m}$ long for female and 142-178 $\mu \mathrm{m}$ long for male, posterior to median bulb. Position of excretory pore posterior to median bulb ca 93-119 $\mu \mathrm{m}$ long for female and 96-115 $\mu \mathrm{m}$ long for male from anterior head end, respectively. Nerve ring surrounding esophageal glands and intestine slightly posterior to pharyngo-intestinal junction. Hemizonid at ca 7.5-10.0 $\mu \mathrm{m}$ posterior to excretory pore for female and 8.0-13.0 $\mu \mathrm{m}$ posterior to excretory pore for male.

\section{Female}

Body smoothly ventrally arcuate when killed by heat (Fig. 1B). Cuticle marked by fine transverse striations, ca. 1.0 $\mu \mathrm{m}$ wide. Lateral field with three lines, ca. $1.8 \mu \mathrm{m}$ wide in midbody (Fig. 1I). Head set off by a distinct constriction, ca. $3 \mu \mathrm{m}$ high, $8 \mu \mathrm{m}$ wide (Fig. 2A). Stylet slender, almost without basal swellings, shaft forming about 2/3 of total stylet length. Procopus cylindrical. Median bulb elongated oval with conspicuous centrally placed valve plates. Oesophageal gland lobe extending dorsally for about five body widths long, down the body. Nerve ring located closely posterior to metacorpus. Ovary anteriorly outstretched. Developing oocytes in multiple rows in ovary. Oviduct tube-like. Spermatheca oval shaped, filled with well-developed sperm. Crustaformeria quadricolumella form, conspicuous. Uterus irregularly rounded. Vagina perpendicular to body surface, slightly inclined anteriorly. Vulval opening with distinctive short vulval flap (Figs. 1D \& E; 2B \& C). Post-uterine sac (PUC) long and conspicuous, i.e., 6-7 vulval body diam. long, often containing sperm. Rectum and anus present, functional. Tail bent ventrally, elongate, conoid shape. Tail tip simple and blunted, no indentation observed before the end.

\section{Male}

Anterior body part and cuticle similar to those of female (Fig. 2E). Tail region strongly ventrally arcuate when killed by heat (Figs. 1B; 2G). Gonad outstretched, sometimes reflexed backwards, occupying $45-55 \%$ of total body length. Spermatocytes and spermatozoa arranged in multiple rows, tightly packed in testis. Tail appearing distinctly claw-like at terminus in lateral view. Lips of cloacal aperture slightly protruding. Spicules paired, relatively straight, rosethorn-shaped. Capitulum of spicule well developed, short condylus with a relatively thin dorsally hooked end (ca. $2 \mu \mathrm{m}$ long) and a pointed short triangular rostrum (ca. $2 \mu \mathrm{m}$ long) with pointed tip. Spicule blade ventrally curved consisting of smoothly and clearly ventrally curved and well cuticularised dorsal limb (Figs. 1F \& H; 2 G $\&$ H). Distal tip of spicule thin, truncate, without cucullus. Gubernaculum absent. Bursal flap present, starting from level of posteriormost genital papillae (P4). Seven genital papillae, i.e., one ventral papilla (P1) and three subventral paired papillae (P2, P3, P4) present: precloacal P1, ventral, 2-3 $\mu \mathrm{m}$ anterior to cloacal opening (CO); P2 on subventral body adanal or slightly anterior to CO; P3 on ventro-subventral body, located mid-way between CO and tail tip; P4 on ventro-subventral body, located at tip of bursal flap or slightly posterior. P4 slightly smaller than P1, P2 and P3. Bursal flap roundish-rectangular to oval in shape, surrounding tail terminus, not indented (Figs. 1G \& H; 2J)

\section{Dauer Juvenile}

Dauer juvenile found under the elytra of $H$. ater. Body slender, 569-635 $\mu \mathrm{m}$ long. Cuticle with smooth surface, fine annulation was observed clearly, lateral lines not seen. Median bulb oval, well-developed, $17.0 \mu \mathrm{m}$ in length $\mathrm{x}$ $10.9 \mu \mathrm{m}$ in width (Figs. A \& B). Metacorpal valve clearly observed, $3.8 \mu \mathrm{m}$ in length x $2.9 \mu \mathrm{m}$ in width, present at middle of, or slightly posterior to, centre of median bulb. Excretory pore not conspicuous. Hemizonid not observed. Cephalic region dome-shaped (Figs. A \& B). Stylet observed with some examined specimens. Pharyngo-intestinal 
junction not conspicuous. Pharyngeal gland lobe not observed. Anus present, conspicuous (Fig. 3D). Tail conical, bluntly pointed (Figs. 3C \& D).

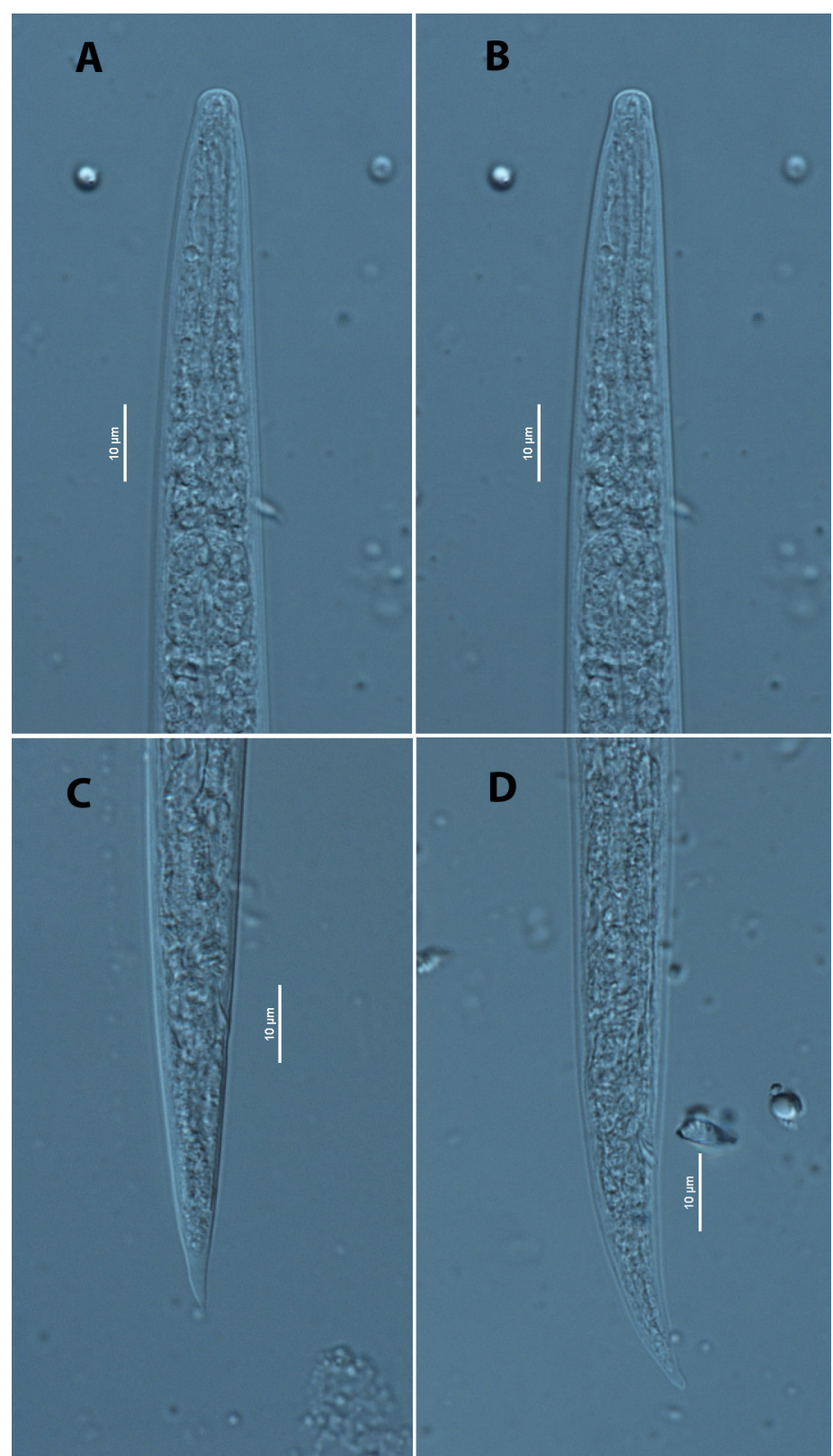

FIG. 3. Light microscope photographs of Bursaphelenchus hildegardae. Dauer juvenile. A-B: Anterior part; C-D: Posterior part. (Scale bars: $\mathrm{A}-\mathrm{D}=10 \mu \mathrm{m})$

\section{HOST AND LOCALITY}

Bursaphelenchus hildegardae, extracted from pine wood (Pinus radiata) and bark beetle (H. ater) samples collected from Kaingaroa Forest in the central North Island of New Zealand (NZ) (38 $24^{\circ} 36.394$ ”S; $\left.176^{\circ} 33^{\prime} 44.989^{\prime \prime} \mathrm{E}\right)$ in March and April 2019; and from Douglas fir (Pseudotsuga menziesii) from Waipori, Dunedin in the South Island of NZ (455 $56^{\prime} 29.222^{\prime \prime} \mathrm{S} ; 170^{\circ} 5^{\prime} 29.27^{\prime}$ E) on 11 November 2020.

\section{MATERIAL EXAMINED}

Seven females (slide nos NNCNZ 3350-3352), seven males (slide nos NNCNZ 3353-3354) and five dauer juveniles (slide nos NNCNZ 3355) from Kaingaroa Forest; five females (slide nos NNCNZ 3356-3358) and three males (slide nos NNCNZ 3359-3362) from Waipori deposited at the National Nematode Collection, New Zealand (NNCNZ). 


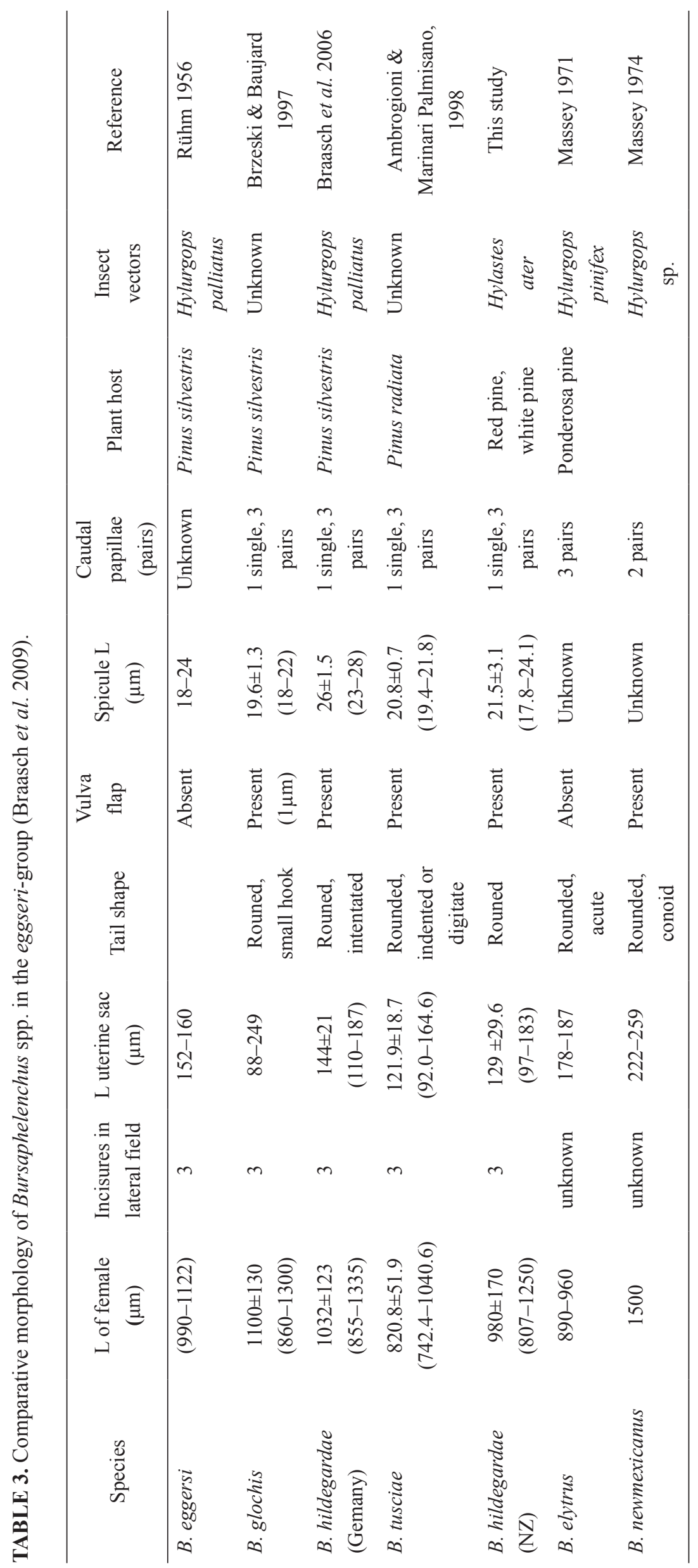




\section{MORPHOLOGICAL DIAGNOSIS AND RELATIONSHIPS}

The New Zealand isolate of $B$. hildegardae is morphologically closest to the original description of $B$. hildegardae (Braasch et al., 2006). However, it varies from the original description in the male with bursa shape, spicule size and $\mathrm{b}$ index. In the original description, it states that the male has a distinct V-shaped dorso-ventrally visible terminal bursa, but in the New Zealand specimens of B. hildegardae it has not been observed (Figs. 1G; $2 \mathrm{G} \& \mathrm{~J}$ ). The spicule sizes were $23-28 \mu \mathrm{m}$ vs $18-24 \mu \mathrm{m}$; and the $\mathrm{b}$ values were $8.6-10.2$ vs $10.2-12.7$ in the German and New Zealand isolates respectively.

The New Zealand isolate of B. hildegardae is also morphologically similar to B. eggersi, B. elytrus Massey, 1971, B. glochis Brzeski \& Baujard, 1997, B. newmexicanus Massey, 1974 and B. tusciae Ambrogioni \& Palmisano, 1998. However, it can be differentiated from them by spicule shape, particularly by the thin hook-like condylus (Table 3).

\section{MOLECULAR PHYLOGENETIC RELATIONSHIPS}

Sequences for partial SSU, D2/D3 and ITS were amplified from a female, male, juvenile and dauer juvenile respectively. These PCR products were subjected to direct sequencing and aligned with those sequences from published $B$. hildegardae data. Comparisons of trees inferred from Bayesian analyses are shown in Figs 4-6. Molecular phylogeny of near full length SSU, D2/D3 expansion segments of LSU and ITS region indicate that the specimen collected in New Zealand is phylogenetically close to B. hildegardae (Figs 4-6). Molecular analyses of an individual female, male, juvenile and dauer juvenile of the nematode confirmed they are the same species. All three trees derived from SSU, D2/D3 and ITS sequences, grouped the New Zealand isolate of $B$. hildegardae together with the isolates of $B$. hildegardae from Germany.

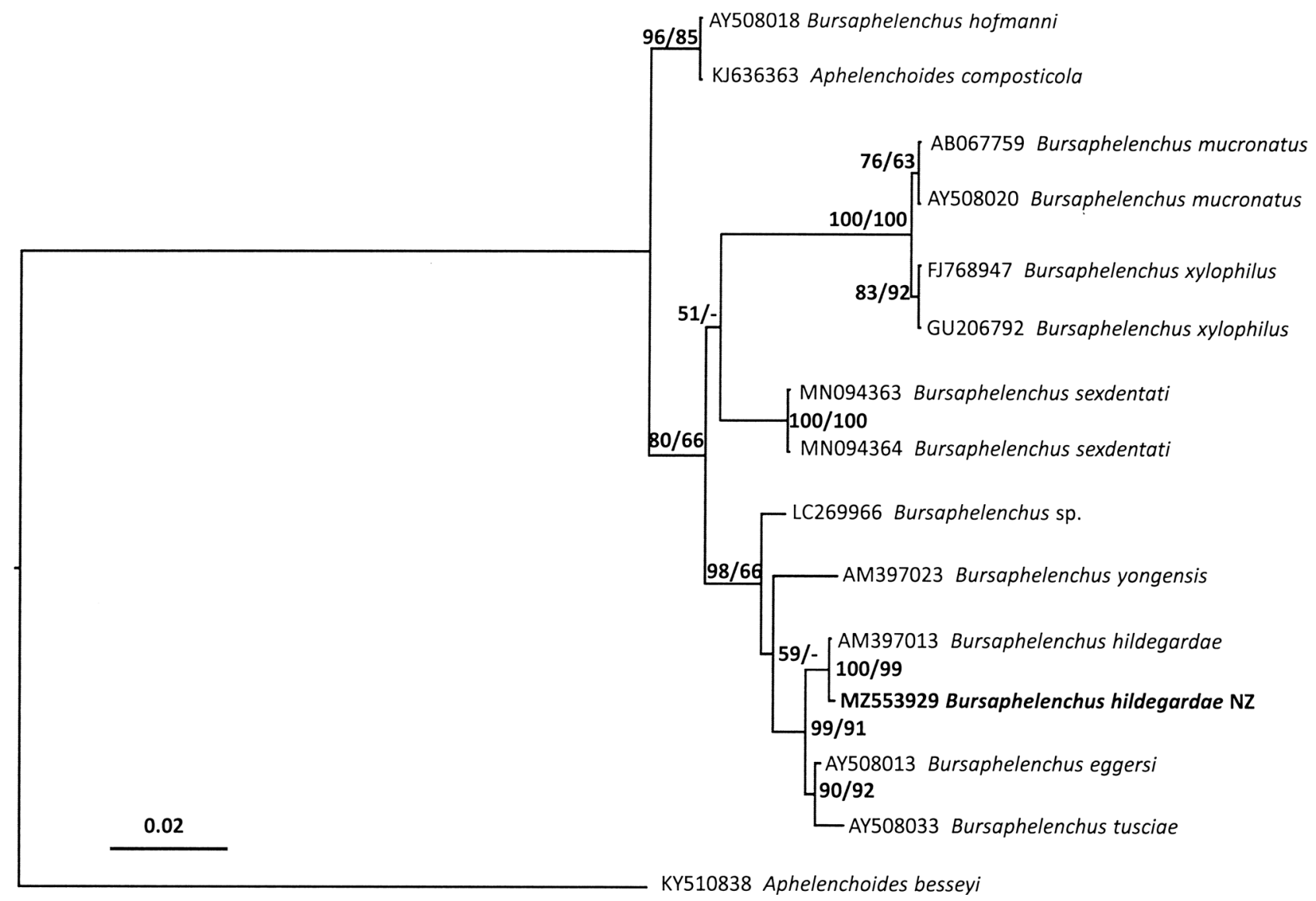

FIG. 4. Bayesian phylogenetic tree inferred from SSU gene DNA sequences of Bursaphelenchus hildegardae. Posterior probabilities greater than $50 \%$ are given on appropriate clades. Nematode species, GenBank accession numbers and locations are listed for each taxon, if known. 
The consensus tree inferred from SSU (Fig. 4) shows that B. hildegardae is clustered with the only SSU sequences of $B$. hildegardae (AM397013) available in GenBank, with a posterior probability of $100 \%$ and a bootstrap of $100 \%$ support, respectively. The results of a BLAST search also showed that New Zealand B. hildegardae is nearly identical to the $B$. hildegardae sequences (AM397013) having $99.9 \%$ with one bp difference, and close to $B$. eggersi (AY508013) having 99.4\% with nine bp difference and B. tusciae (AY08033) having 98.9\% with 16 bp difference for the $18 \mathrm{~S}$ sequences.

The consensus tree inferred from LSU (Fig. 5) shows that the New Zealand isolate of B. hildegardae is grouped with the only LSU sequences of $B$. hildegardae (AM396569) available in GenBank, with a posterior probability of $100 \%$ and a bootstrap of $100 \%$ support respectively. From the results of a BLAST search, the sequences of $28 \mathrm{~S}$ from the New Zealand isolate were almost identical to the only B. hildegardae sequences (AM396569) having 99.7\% with two bp difference. It is also close to two B. eggersi sequences (AY508078 and MW258275) having 95.9\% and 95.8\%, and two B. tusciae sequences (AY508104 and MW358271) having 96.4\% and 96.5\% identity for the $28 \mathrm{~S}$ sequences, respectively.

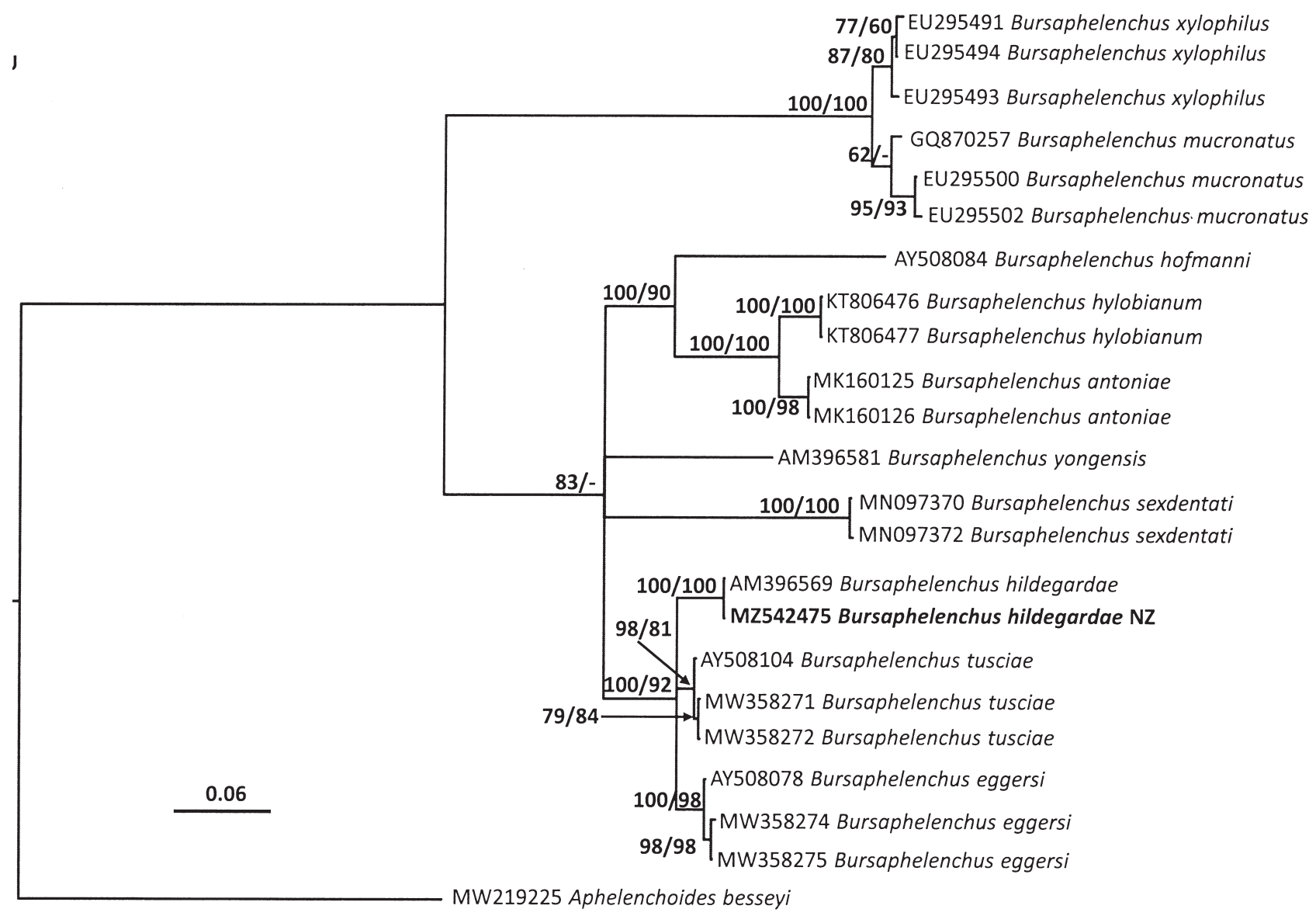

FIG. 5. Bayesian phylogenetic tree inferred from D2D3 gene DNA sequences of Bursaphelenchus hildegardae. Posterior probabilities greater than $50 \%$ are given on appropriate clades. Nematode species, GenBank accession numbers and locations are listed for each taxon, if known.

The consensus tree inferred from ITS (Fig. 6) shows that the New Zealand isolate of B. hildegardae is monophyletic with a posterior probability of $100 \%$ (a bootstrap of $100 \%$ ) when two ITS sequences of $B$. hildegardae (AM269736 and HQ197354) available in GenBank are included. The results of a BLAST search showed that the sequences of ITS from the New Zealand isolate were $100 \%$ identical to the B. hildegardae sequences (AM269736) and close to a sequences from Spain (HQ197354) having 99.48\% identity for the ITS sequences, respectively. 


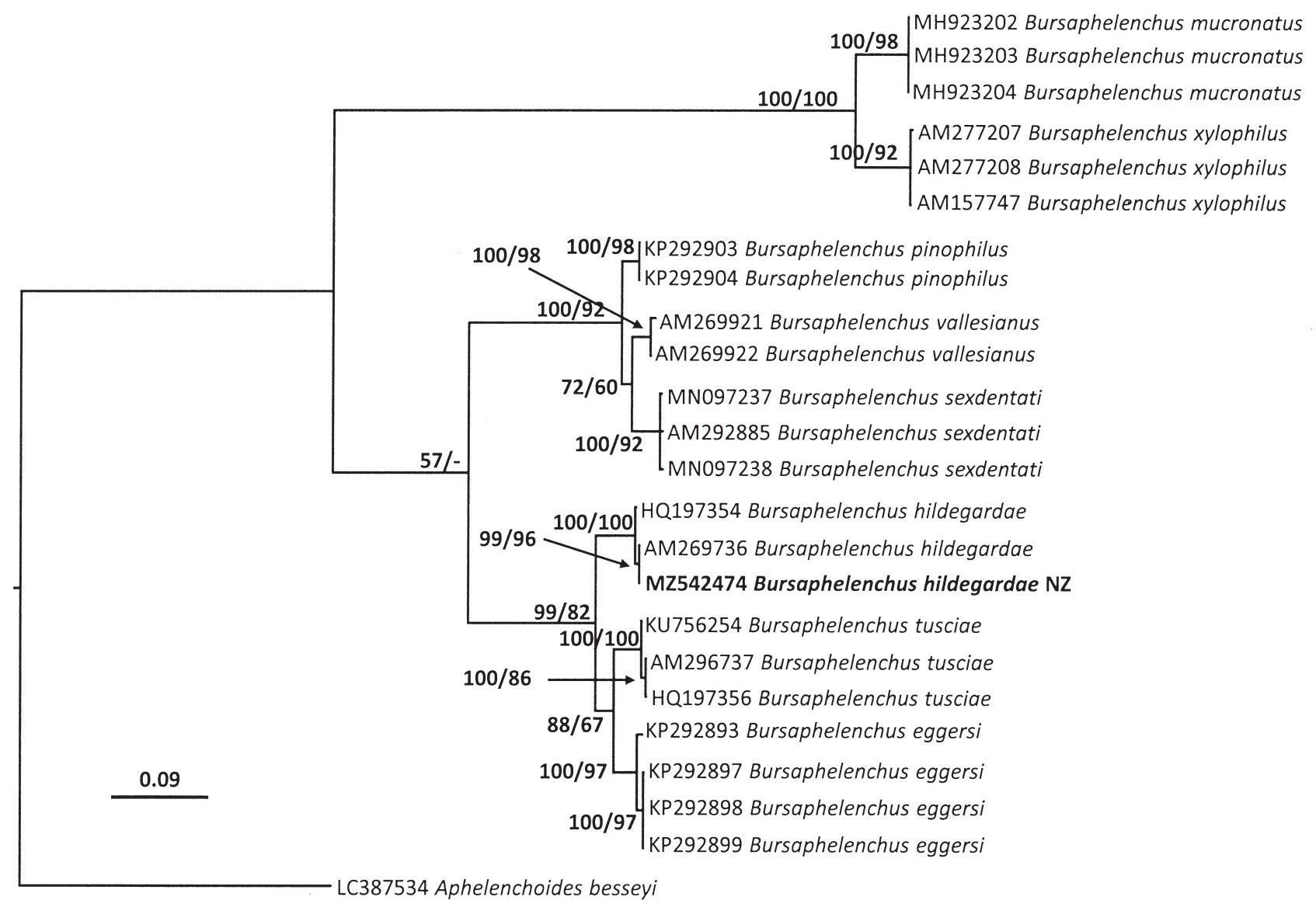

FIG. 6. Bayesian phylogenetic tree inferred from ITS gene region DNA sequences of Bursaphelenchus hildegardae. Posterior probabilities greater than $50 \%$ are given on appropriate clades. Nematode species, GenBank accession numbers and locations are listed for each taxon, if known.

\section{Discussion}

Bursaphelenchus hildegardae was described from Germany from Pinus silvestris and the dauer juvenile was found under the elytra of a beetle, Hylurgops palliatus (Gyllenhal, 1813) (Braasch et al., 2006). Since then it has been isolated in Spain from congeneric pine trees (P. nigra, P. pinaster and P. silvestris) in 2010, 2012, 2018 and 2019 (A.A. Argibay, pers. comm; Zamora et al. 2016). Later on, it was detected from pine trees in Australia in 2016 (Carnegie \& Nahrung, 2019). No further record is known anywhere in the world.

This is the first record of $B$. hildegardae in New Zealand and the second report from the southern hemisphere in addition to Australia. However, this species may have been present in the country for a long time. $B$. hildegardae is morphologically similar to B. eggersi and both species belong to the eggersi-group (Braasch, 2001; Braasch et al., 2006). As B. hildegardae was described in 2006, it is likely that Dale had isolated B. hildegardae in 1967 but identified this nematode as the closest organism known at the time - B. eggersi. Dale (1967) reported that he isolated $B$. eggersi from the bark beetle $H$. aster in eight of 14 sites across the North and South Islands of New Zealand. In the current study, B. eggersi was not found from any of the pine samples or $H$. ater specimens. This is further evidence, suggesting that $B$. hildegardae (but not $B$. eggersi) may have been well established in New Zealand for a long time but previously misidentified. So far, the nematode has not been recorded to cause problems to pine trees.

A range of information was used to assess the potential economic impact of $B$. hildgardae in New Zealand, which included searching the literature and consulting experts of this group of nematodes. Based on current limited literature on the overall effects for B. hildegardae, it was concluded that: 1) further information about the status of this nematode in New Zealand is likely to emerge as a result of any ongoing surveillance and diagnostic work that might be associated with managing pine forest problems; and 2) pathogenicity of $B$. hildegardae needs to be further studied. 
Bursaphelenchus hildegardae belongs to the eggersi-group with five other members, viz., B. eggersi, B. elytrus, B. glochis, B. newmexicanus and B. tusciae. The key below to the known species of eggersi-group was designed.

\section{Key to $B$. hildegardae and nematodes in the eggersi-group}

1. Male caudal papillae 2 pairs; longer body $(1500 \mu \mathrm{m}$ for female, $1250 \mu \mathrm{m}$ for male $) \ldots \ldots$.......... B. newmexicans

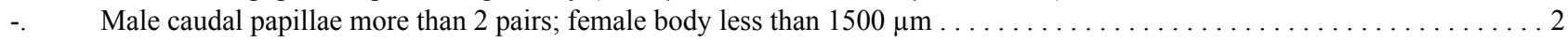

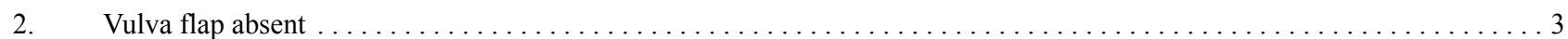

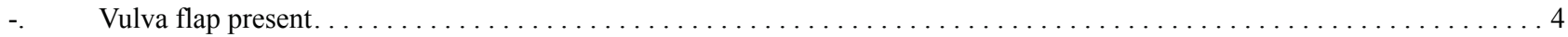

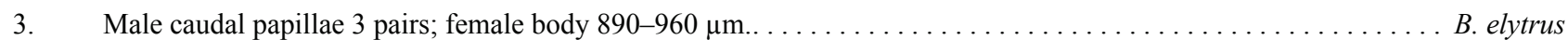

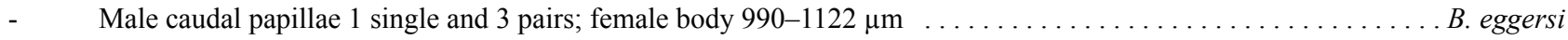

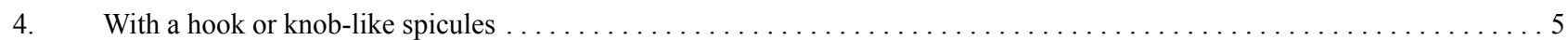

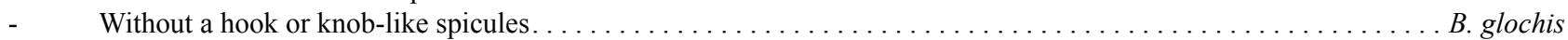

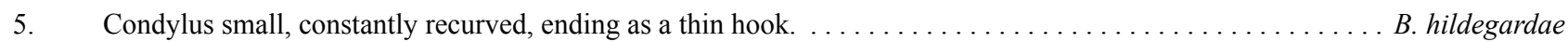

- Condylus variably recurved, formed with a depressed centre, a thicker, sometimes knob-like end . . . . . . . . . B. tusciae

\section{Acknowledgements}

The initial sampling of the nematodes was part of a Forest Health Assessment (FHA) programme funded and implemented in Kaingaroa Timberlands (KT) Ltd. estate. The diagnostics was jointly funded by the Forest Growers Levy Trust and Plant Health \& Environment Mycology \& Bacteriology Team. SPS undertook all the field work during the delimiting survey in the Kaingaroa Forest; KT assisted with providing access to their property, supplying tree fellers and addressing various logistic/communication issues. We thank Ruth Griffin, Alice Merrall and staff in the Mycology \& Bacteriology team, MPI for nematode extraction and PCR laboratory work; Stephanie Sopow, Stephen Pawson, Carl Wardhaugh and other SCION staff for the overall support especially with supplying historical beetle collection specimens for study. Our gratitude also goes to our colleague Dr Jianfeng Gu, Ningbo Customs Technology Center, Zhejiang, China for discussion on species identifications. Two anonymous reviewers are thanked for comments on the manuscript. This research project was supported by core funding for Crown Research Institutes from the Ministry of Business, Innovation and Employment's Science and Innovation Group.

\section{References}

Abolafia, J., Alizadeh, M. \& Khakvar, R. (2016) Description of Panagrellus ulmi sp. n. (Rhabditida, Panagrolaimidae) from Iran, and comments on the species of the genus and its relatives. Zootaxa, 4162 (2), 245-267. https://doi.org/10.11646/zootaxa.4162.2.3

Altschul, S.F., Gish, W., Miller, W., Myers, E.W. \& Lipman, D.J. (1990) Basic local alignment search tool. Journal of Molecular Biology, 215, 403-410. https://doi.org/10.1016/S0022-2836(05)80360-2

Ambrogioni, L. \& Marinari Palmisano, A. (1998) Description of Bursaphelenchus tusciae sp. n. from Pinus pinea in Italy. Nematologia Mediterranea, 26, 243-254.

Braasch, H. (2001) Bursaphelenchus species in conifers in Europe: distribution and morphological relationships. EPPO Bulletin, $31,127-142$. https://doi.org/10.1111/j.1365-2338.2001.tb00982.x

Braasch, H. (2009) Re-establishment of Devibursaphelenchus Kakuliya, 1967 (Nematoda, Aphelenchoididae) and proposal for a new combination of several Bursaphelenchus. Journal of Nematode Morphology and Systematics, 12, 1-5.

Braasch, H., Burgermeister, W., Schönfeld, Metge, K. \& Brandstetter, M. (2006) Bursaphelenchus hildegardae sp. n. (Nematoda: Parasitaphelenchidae) - a new species belonging to the 'eggersi' group. Journal of Nematode Morphology and Systematics, 9, 27-36.

Brzeski, M.W. \& Baujard, P. (1997) Morphology and morphometrics of Bursaphelenchus (Nematoda: Aphelenchoididae) species from pine wood of Poland. Annales Zoologici, 47, 305-319.

Carnegie, A.J. \& Nahrung, H.F. (2019) Post-Border Forest Biosecurity in Australia: Response to Recent Exotic Detections, 
Current Surveillance and Ongoing Needs. Forests, 10 (4), 236.

https://doi.org/10.3390/f10040336

Dale, P. (1967) Nematodes associated with pine-bark beetle, Hylastes ater in New Zealand. New Zealand Journal of Science, $10(1), 222-234$.

Dale, P. (1971) Foliar, root lesion, and other nematodes. New Zealand Journal of Agriculture, 122, 59-61.

Davies, K. \& Giblin-Davis, R.M. (2004). The biology and associations of Fergusobia (Nematoda) from the Melaleuca leucadendra-complex in eastern Australia. Invertebrate Systematics, 18, 291-319. https://doi.org/10.1071/IS02034

Holterman, M., Van Der Wurff, A., Van Den Elsen, S., Van Megen, H., Bongers, T., Holovachov, O., Bakker, J. \& Helder, J. (2006) Phylum-wide analysis of SSU rDNA reveals deep phylogenetic relationships among nematodes and accelerated evolution toward crown clades. Molecular Biology and Evolution, 13, 1792-1800. https://doi.org/10.1093/molbev/ms1044

Kanzaki, N. \& Giblin-Davis, R.M. (2018) Diversity and plant pathogenicity of Bursaphelenchus and related nematodes in relation to their vector interactions. Current Forestry Reports, 4, 85-100. https://doi.org/10.1007/s40725-018-0074-7

Kanzaki, N., Tsujimoto, S. \& Kajimura, H. (2021) Bursaphelenchus hibisci n. sp. (Nematoda: Aphelenchoididae) isolated from Ernoporus corpulentus (Scolytinae) emerged from dead Hibiscus tiliaceus (Malvaceae) twigs from Okinawa, Japan. Nematology. [in press] https://doi.org/10.1163/15685411-bja10109

Knight, K.W.L., Barber, C.J. \& Page, G.D. (1997) Plant-parasitic nematodes of New Zealand recorded by host association. Journal of Nematology, 29, 640-656.

Larkin, M.A., Blackshields, G., Brown, N.P., Chenna, R., McGettigan, P.A., McWilliam, H., Valentin, F., Wallace, I.M., Wilm, A., Lopez, R., Thompson, J.D., Gibson, T.J. \& Higgins, D.G. (2007) Clustal W and Clustal X version 2.0. Bioinformatics, 23, 2947-2948. https://doi.org/10.1093/bioinformatics/btm404

Massey, C.L. (1971) Nematode associates of several species of Pissodes (Coleoptera: Curculionidae) in the United States. Annals of Entomological Society of America, 64, 162-169. https://doi.org/10.1093/aesa/64.1.162

Massey, C.L. (1974) Biology and taxonomy of nematode parasites and associates of bark beetles in the United States. Agriculture Handbook No. 446. USDA, Forest Service, Washington, v + 233 pp.

Nunn, G.B. (1992) Nematode molecular evolution. Ph.D. Thesis, University of Nottingham, Nottingham. [unknown pagination]

Posada, D. \& Crandall, K.A. (1998) Modeltest: testing the model of DNA substitution. Bioinformatics, 14, 817-818. https://doi.org/10.1093/bioinformatics/14.9.817

Ronquist, F. \& Huelsenbeck, J.P. (2003) MR BAYES: Bayesian inference of phylogenetic trees. Bioinformatics, 19, 15721574. https://doi.org/10.1093/bioinformatics/btg180

Rühm, W. (1956) Dien Nematoden der Irpiden. Parasitologische Schriftenreihe, 6, 1-435.

Ryss, A., Vieira, P., Mota, M.M. \& Kulinich, O. (2005) A synopsis of the genus Bursaphelenchus Fuchs, 1937 (Aphelenchida: Parasitaphelenchidae) with keys to species. Nematology, 7, 393-458. https://doi.org/10.1163/156854105774355581

Ryss, A.Y. \& Subbotin, S.A. (2017) [Coevolution of wood-inhabiting nematodes of the genus Bursaphelenchus Fuchs, 1937 with their insect vectors and plant hosts]. Zhurnal Obshchei Biologii, 78, 32-61. [in Russian]

Swofford, D.L. (2002) PAUP*. Phylogenetic Analysis Using Parsimony (and Other Methods), Version 4. Sinauer Associates, Sunderland, Massachusetts. [program]

White, T.J., Bruns, T., Lee, S. \& Taylor, J.W. (1990) Amplification and direct sequencing of fungal RNA genes for phylogenetics. In: Innis, M.A., Gelgard, D.H., Sninsky, J.J. \& White, T.J. (Eds.), PCR Protocols: A Guide to Methods and Applications. Academic Press, New York, pp. 315-322. https://doi.org/10.1016/B978-0-12-372180-8.50042-1

Whitehead, A.G. \& Hemming, J.R. (1965) A comparison of some quantitative methods of extracting small vermiform nematodes from soil. Annals of Applied Biology, 55, 25-38. https://doi.org/10.1111/j.1744-7348.1965.tb07864.x

Williams, B.D., Schrank, B., Huynh, C., Shownkeen, R. \& Waterston, R.H. (1992) A genetic mapping system in Caenorhabditis elegans based on polymorphic sequence-tagged sites. Genetics, 131, 609-624. https://doi.org/10.1093/genetics/131.3.609

Yeates, G.W. (2010) Phylum Nematoda: roundworms, eelworms. In: Gordon, D.P. (Ed.), New Zealand Inventory of Biodiversity. Vol. 2. Kingdom Animalia. Chaetognatha, Ecdysozoa, Ichnofossils. Canterbury University Press, Christchurch, pp. 480493.

Zamora, P., Sanz-Ros, A.V.,Dueñas, M., Miranda, J., Álvarez, B., González, A., Mayor, E., Dominguez, J. C., Pérez, G., Martín, A. B., Renedo, F. \& Rodríguez, V. (2016) species DE Bursaphelenchus sp. en coníferas de la región de castilla y león. Post-262. XVIII Congreso de la Sociedad Española de Fitopatología, Palencia, 20-23 Septiembre 2016. Available from: 
https://sef.es/sites/default/files/Libro_SEF_2016_Palencia_sin_imagenes_pdf (accessed on 9 July 2021) [in Spanish]

Zhao, Z.Q. \& Buckley, T.R. (2009) Phylogenetic analysis of nematode nuclear 18S rDNA sequences indicates the genus Tripylina Brzeski, 1963 (Nematoda: Tripylidae de Man, 1876) should be placed in Enoplida. Zootaxa, 2238 (1), 25-32.

https://doi.org/10.11646/zootaxa.2238.1.2

Zhao, Z.Q., Li, D.M., Davies, K.A. \& Ye, W. (2015) Schistonchus zealandicus n. sp. (Nematoda: Aphelenchoididae) associated with Ficus macrophylla in New Zealand. Nematology, 17, 53-66.

https://doi.org/10.1163/15685411-00002851

Zheng, J.W., Subbotin, S.A., He, S.S., Gu, J.F. \& Moens, M. (2002) Molecular characterisation of some Asian isolates of Bursaphelenchus xylophilus and B. mucronatus using PCR-RFLPs and sequences of ribosomal DNA. Russian Journal of Nematology, 11, 17-22. 